\title{
Clinical Analysis on the Effectiveness of Conservative Compression Suture Technique to Conserve Fertility on Pernicious Placenta Previa
}

\author{
Krishna Pyari Duguju1 ${ }^{*}$, Jin He1*, Shuxin Li1 ${ }^{1}$ Ashu Shrestha², Nasrat Rahim1, Yanhong Shan1\# \\ ${ }^{1}$ Department of Obstetrics and Gynecology, The First Hospital of Jilin University, Changchun, China \\ ${ }^{2}$ Department of Radiology, China-Japan Union Hospital of Jilin University, Changchun, China \\ Email: drpyari01@gmail.com, hejin1204@163.com, 17760734614@163.com, shresthaashu@gmail.com, \\ nasrat.rahim@yahoo.fr, "shanyanhong2008@126.com
}

How to cite this paper: Duguju, K.P., He, J., Li, S.X., Shrestha, A., Rahim, N. and Shan, Y.H. (2019) Clinical Analysis on the Effectiveness of Conservative Compression Suture Technique to Conserve Fertility on Pernicious Placenta Previa. Open Journal of Obstetrics and Gynecology, 9, 62-72. https://doi.org/10.4236/ojog.2019.91007

Received: December 24, 2018

Accepted: January 12, 2019

Published: January 15, 2019

Copyright $\odot 2019$ by author(s) and Scientific Research Publishing Inc. This work is licensed under the Creative Commons Attribution International License (CC BY 4.0).

http://creativecommons.org/licenses/by/4.0/

\begin{abstract}
Objective: To evaluate the effectiveness of conservative compression surgical suture techniques used for the management of pernicious placenta previa to conserve fertility in the subsequent pregnancies. Study Design: This was a non-comparative retrospective study of 188 patients diagnosed with pernicious placenta previa who underwent cesarean section in The First Hospital of Jilin University, China, from 1 January 2013 to 1 January 2018. Successful group was defined as those in which the intraoperative bleeding was managed by either modified $\mathrm{CHO}$ or by B-lynch suture technique and those who had further intervention including hysterectomy were designated as failure group. Results: Out of 217 patients, 188 met inclusion criteria and 29 patients were excluded. In 188 cases, 183 (97.34\%) cases successes and 5 (2.65\%) cases had hysterectomy. Among included group, 118 patients $(62.76 \%)$ had undergone emergency cesarean section and 70 patients (37.23\%) underwent elective cesarean section. The emergency group had significantly lesser gestation period of gestation at the time of cesarean section $(P=0.021)$ and lower neonatal weight $(\mathrm{P}=0.001)$ than that of elective group. The estimated blood loss during surgery was $500-3200 \mathrm{ml}$ (mean: $925 \mathrm{ml}$ ). Additionally, the amount of bleeding was found to be significantly more in patient with intraoperative complication $(\mathrm{P}=0.007)$ and in patient with implanted placenta $(\mathrm{P}<0.001)$. Conclusion: The conservative compression suture technique including modified $\mathrm{CHO}$ and B-lynch suture technique during the cesarean delivery is a feasible, safe and effective alternative conservative surgical technique for the management of bleeding in case of pernicious placenta previa. Besides good
\end{abstract}

*These authors contribute equally to this work. 
surgical outcome and proper neonatal result this technique also reduces the rate of hysterectomy, thus conserving the fertility.

\section{Keywords}

Pernicious Placenta Previa, Conservative Compression Suture Techniques, Cesarean Section, Hysterectomy, Fertility

\section{Introduction}

In recent times, the frequency of cesarean section (CS) delivery has increased to unprecedented stages, resulting in growing obstetrical sequelae [1]. In addition to short-term risks, CS delivery can lead to complications in successive pregnancies, including cesarean scar pregnancy with life-threatening haemorrhage, placenta accrete, placenta previa, abnormal uterine bleeding following surgery, uterine rupture and diminished subsequent fertility [2] [3].

Pernicious placenta Previa (PPP) is an obstetric complication defined as placenta previa adherent to prior CS scars often accompanied with placenta accrete. Chattopadhyay et al. first described the pernicious placenta previa in their study [4]. Recent literature had shown that the incidence of PPP has progressively increased in developing countries like China due to the steady rise in CS delivery and implementation of two-child policy [5]. It can lead to massive postpartum haemorrhage complicated by shock and increases the risk of maternal mortality.

The treatment of PPP is a main question amongst the obstetrician. Currently, several adjuvant hemostatic techniques including, internal iliac artery ligation, interventional arterial radioembolization, balloon occlusion of the artery are used to minimize intraoperative blood loss and in very severe circumstances hysterectomy is done [6] [7] [8]. Though, all of these above techniques have their own limitation and conservation of fertility in consequent pregnancies is an important issue. The objective of the present study was to investigate the efficiency of various surgical suture techniques used in our hospital in the management of PPP to conserve fertility in the subsequent pregnancy.

\section{Methods}

A non-comparative retrospective study was conducted among 217 consecutive women with placenta previa who were admitted to the Department of Obstetrics of the First Affiliated Hospital of Jilin University from January 1, 2013, to January 1,2018 . This study followed the tenets of the Declaration of Helsinki and was approved by the ethics committee of the First Affiliated Hospital of Jilin University. Informed written consent was acquired from each patient prior to their involvement in the study. Among 217, 188 women with placenta previa were included and 29 women were excluded (Figure 1). Women were recruited with 


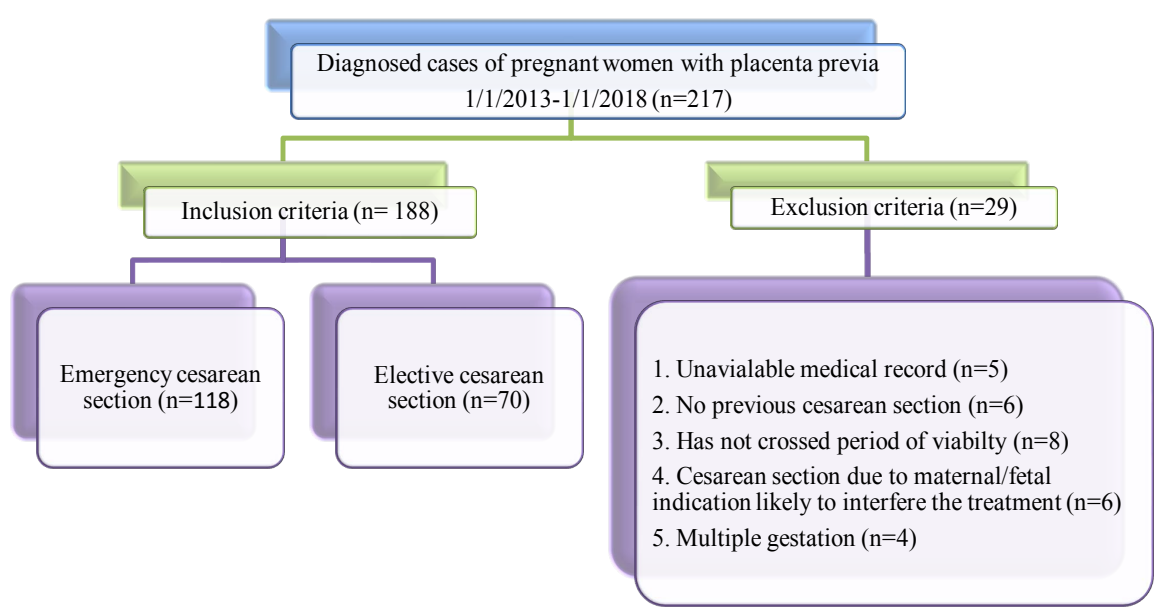

Figure 1. Study population flowchart.

positive sonographic (USG) or magnetic resonance imaging (MRI) evidence of placenta previa, all the cases which had crossed a period of viability and with past history of at least one cesarean section. Those with unavailable medical records and lost to follow-up, multiple gestations, women with past history of bleeding disorders expected to affect amount of bleeding, patient with uterine myoma or fibroid, cesarean section due to maternal/fetal indication such as chronic medical condition: psychiatric disorders, fetal distress; likely to interfere the treatment were excluded. Emergency CS was done in the patient with severe uncontrolled vaginal bleeding during the period of observation and is less than 36 weeks as well as refractive to conservative management. Those patients with controlled vaginal bleeding with conservative management were recruited for elective CS. Prenatal diagnosis has established on USG or MRI finding and a history of previous CS. The abnormal placental position was further established either clinically, or by histopathological examination and after delivery.

\subsection{Surgical Methods}

Before the procedure, all the patients were observed as well as counselled by a multidisciplinary team that included an obstetrician, an anesthesiologist, urologist, surgeon, invasive radiologist, and neonatologist.

\subsection{Preoperative Preparation}

All the patients had the same preoperative preparation, all in the sterile obstetrics operation room. PPP is often associated with placental implantation deep to uterine serosa, invading the posterior wall of the bladder. In such cases, bladder and anterior wall of uterus are adhered to each other, which lead to difficult placental delivery and massive postpartum haemorrhage. Bladder and ureter can be injured during adhenolysis process. Sufficient preoperative preparation is important in pernicious placenta previa. Preoperative preparation includes blood and blood products, ureter stent, cystoscopy, central venous catheter. 


\subsection{Anaesthesia}

Among 188 patients, 93 patient received combined spinal and epidural anaesthesia, 72 patients lumbar and hard combined with general anaesthesia, 18 patients were operated under general anaesthesia, while 5 patients were operated under spinal.

\subsection{Surgical Procedure}

Under the influence of anaesthesia patient was catheterized and placed in the Lloyd Davies position. The abdomen was opened in layers, Pfannenstiel incision was given in skin and removal of the previous scar was carried out. In most of the cases, due to previous cesarean section pelvic adhesion is more likely in PPP. Careful pelvic adhenolysis was done for the better view of the operation field. Lower uterine segment was identified after opening the peritoneum. Furthermore, careful bladder dissection and reflection of the bladder was done to avoid bladder injury. After the uterine incision at the lower uterine segment, the uterine cavity was opened by tearing the uterine muscle layer and the uterine cavity is evacuated. Finally, delivery of baby and placenta was done carefully. Placental bed was checked for bleeding points. Oxytocin $10 \mathrm{U}$ was injected in the fundus of the uterus after delivery of the fetus. Two doses of Hemabate (prostaglandinF2 $\alpha$ ) $250 \mu \mathrm{g}$ given immediately after oxytocin injection, one into the fundus of the uterus and another into the deltoid muscle of mother. Firstly, in all the bleeding cases bimanual compression was done. In uncontrolled bleeding cases even after bimanual compression, surgical suture techniques were used.

In our hospital, if bimanual compression fails to control bleeding modified $\mathrm{CHO}$ suture technique was used and in atonic cases, B-lynch suture technique was done. In modified $\mathrm{CHO}$ suture technique, one of the uterine walls was sutured. Multiple square sutures were applied. In most cases, this suture technique had been successful to achieve hemostasis. Few cases went into atony. The atonic cases were managed with B-lynch suture technique.

\subsection{Statistical Analysis}

Data were analyzed using the statistical software package IBM SPSS Statistics 21. Data were expressed as mean $(\mathrm{M}) \pm$ standard deviation (SD) if normally distributed, and Independent sample t-test was used for statistical comparison. Non normally distributed data were expressed as Median (P25, P75), and analysis was performed using Mann-Whitney-Wilcoxon test. $\mathrm{X}^{2}$ examination was used to count data comparison. A two-sided $\mathrm{P}$ value $<0.05$ was considered to be statistically significant.

\section{Results}

\subsection{Study Population}

We assessed 217 pregnant women with a preoperative diagnosis of placenta previa who underwent CS during the study phase. After revising all the medical and 
surgical records 188 patients were included for further analysis, and 29 patients were excluded as explained in Figure 2. Amongst 188 women, 118 patients $(62.76 \%)$ had undergone emergency CS and 70 patients $(37.23 \%)$ underwent elective CS. The epidemic, as well as clinical descriptions of 188 patients with PPP who underwent CS, are concise in Table 1. At the time of CS, the mean maternal age was $32.4 \pm 4.3$ years (range: $22-47$ years), the mean gravidity was 3 (Range: 2 - 4), the mean of previous CS was $1.1 \pm 0.4$ (Range: 1 - 2) and the mean gestational age at the time of CS was $36.1 \pm 2.7$ weeks (Range: $30.2-40$ weeks). Additionally, 69 patients had placental implantation.

\subsection{Operative Circumstances and Neonatal Outcome}

In all the patients CS (elective or emergency) along with modified $\mathrm{CHO}$ suture placement was performed. In uncontrolled bleeding cases additionally, B-lynch suture was applied. The summary of intra, as well as post-operative status and neonatal outcomes of the patients, is summarized in Table 2. The estimated blood loss during surgery was 500 - $3200 \mathrm{ml}$ (mean: $925 \mathrm{ml}$ ). Among all patients who underwent the procedure, 53 patients had an intra-operative complication. In 6 patients' severe bladder injury was noticed and underwent bladder injury repair, 17 patients underwent uterine injury repair and adhesion release surgery was done in 9 patients. Whereas, in 5 patients the bleeding was not controlled by any means and hysterectomy was performed. Moreover, ureter stent was placed in 28 patients and further Blynch suture was positioned in 26 patients. Regarding the neonatal outcome, the mean birth weight was $2803 \pm 635$ grams and the mean Apgar score was $9.3 \pm 1.1$.

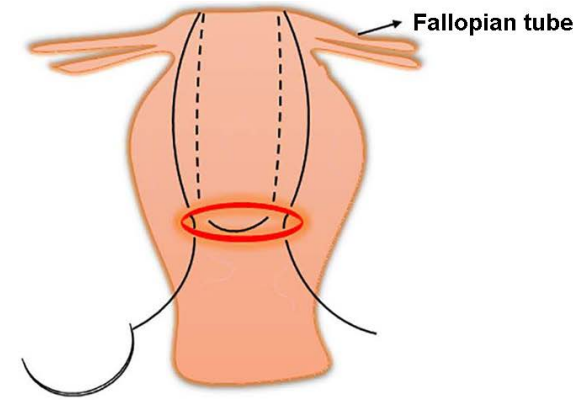

(a) Anterior view

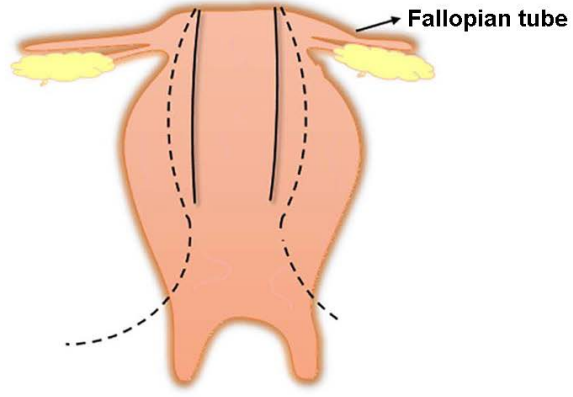

(b) Posterior View

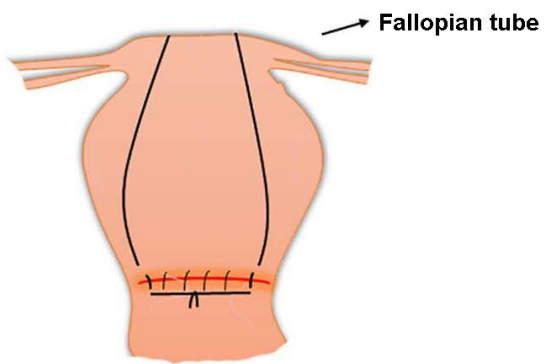

(c) Anterior View

Figure 2. B-lynch suture technique. 
Table 1. Epidemic and clinical data of all patient included in the study.

\begin{tabular}{ccc}
\hline Variable & Mean \pm Standard deviation & Range \\
\hline Maternal age (Years) & $32.4 \pm 4.3$ & $22-47$ \\
Number of previous caesarean section & $1.1 \pm 0.4$ & $1-2$ \\
Gestation at caesarean section (weeks) & $36.1 \pm 2.7$ & $30.2-40$ \\
Gravidity & 3 & $2-4$ \\
Placental implantation & 69 & \\
\hline
\end{tabular}

Table 2. Operative circumstances and neonatal outcome.

\begin{tabular}{ccc}
\hline Variable & Mean & Range \\
\hline amount of bleeding (ml) & 925 & $500-3200$ \\
duration of operation (minutes) & 103 & $84-130$ \\
length of preoperative stay & 4 & $2-11$ \\
Gestational age of the newborn (weeks) & $36.1 \pm 2.7$ & $30.2-40$ \\
Neonatal weight (grams) & $2803 \pm 635$ & \\
Apgar score & $9.3 \pm 1.1$ & \\
\hline
\end{tabular}

\subsection{Emergency and Elective CS}

Among the included patients, 70 (37.23\%) had undergone elective CS and 118 patients (62.76\%) had undergone emergency CS. The results of the comparison of the epidemic and clinical data, intraoperative and post-operative conditions, complications and neonatal outcome between the elective and emergency group are summarized in Table 3. Regarding the epidemic and clinical data, there was no difference in maternal age $(\mathrm{P}=0.774)$, gravidity $(\mathrm{P}=0.520)$, number of previous $\mathrm{CS}(\mathrm{P}=0.380)$ and placenta implantation $(\mathrm{P}=0.088)$ between the two groups. However, the emergency group had significantly lesser gestation period at the time of termination of pregnancy $(\mathrm{CS})(\mathrm{P}=0.021)$ than the elective group.

In term of intraoperative and post-operative conditions, there was no significant difference in the amount of bleeding $(P=0.208)$, duration of operation (0.268), length of postoperative stay $(\mathrm{P}=0.055)$ as well as postoperative fever $(\mathrm{P}=0.673$ ) between the elective and emergency group (Table 3$)$. As regards the complication, 19 patients in the elective group and 34 patients in the emergency group have complication during the procedure. Since the $\mathrm{P}$-value is greater than $0.05(\mathrm{P}=0.739)$ concluded that there is no significant difference in the complication between the two groups.

Regarding the neonatal outcome, there were two variables including the APGAR score and the neonatal weight (gm). There was no significant difference in the APGAR score $(\mathrm{P}=0.625)$ between the two groups. However, neonatal weight $(\mathrm{P}=0.001)$ was found to be significantly higher in the elective group than that of the emergency group. 
Table 3. Comparison between elective and emergency CS.

\begin{tabular}{|c|c|c|c|c|c|}
\hline & Variable & $\begin{array}{c}\text { Elective } \\
\mathrm{n}=70(37.23 \%)\end{array}$ & $\begin{array}{c}\text { Emergency } \\
\mathrm{n}=118(62.76 \%)\end{array}$ & $\begin{array}{l}\text { Statistical } \\
\text { magnitude }\end{array}$ & P Value \\
\hline \multirow{5}{*}{$\begin{array}{l}\text { Epidemic and } \\
\text { clinical data }\end{array}$} & Maternal age & $32.63 \pm 3.85$ & $32.45 \pm 4.82$ & 0.287 & 0.774 \\
\hline & Gravidity & $3(2,4)$ & $3(2,4)$ & -0.644 & 0.520 \\
\hline & $\begin{array}{c}\text { Gestation at } \\
\text { termination caesarean } \\
\text { section (weeks) }\end{array}$ & $36.14 \pm 3.51$ & $34.82 \pm 4.11$ & 2.339 & 0.021 \\
\hline & Placenta implantation & 31 & 38 & 2.901 & 0.088 \\
\hline & $\begin{array}{l}\text { Number of previous } \\
\text { cesarean section }\end{array}$ & $1.07 \pm 0.35$ & $1.13 \pm 0.44$ & -0.880 & 0.380 \\
\hline \multirow{4}{*}{$\begin{array}{c}\text { Intraoperative } \\
\text { and } \\
\text { post-operative } \\
\text { data }\end{array}$} & $\begin{array}{l}\text { Amount of bleeding } \\
(\mathrm{ml})\end{array}$ & $1000(500,3200)$ & $850(500,1600)$ & -1.259 & 0.208 \\
\hline & $\begin{array}{c}\text { Duration of } \\
\text { operation(minute) }\end{array}$ & $116(86,137)$ & $101(84,133)$ & -1.108 & 0.268 \\
\hline & $\begin{array}{c}\text { Length of } \\
\text { postoperative stay }\end{array}$ & $5(3,12)$ & $4.5(2,9)$ & -1.917 & 0.055 \\
\hline & Postoperative fever & 20 & 38 & 0.178 & 0.673 \\
\hline Complications & Complications & 19 & 34 & 0.111 & 0.739 \\
\hline \multirow{2}{*}{$\begin{array}{l}\text { Neonatal } \\
\text { outcome }\end{array}$} & Apgar Score & $9.30 \pm 1.28$ & $9.21 \pm 1.07$ & 0.490 & 0.625 \\
\hline & Neonate weight (gm) & $2955.61 \pm 519.75$ & $2631.93 \pm 709.91$ & 3.235 & 0.001 \\
\hline
\end{tabular}

\subsection{Factor Affecting the Amount of Bleeding}

The comparison between the predictive factors such as maternal age, gravidity, number of previous CS, gestational age at termination of pregnancy, placental implantation, types of CS, complication during surgery, length of hospital stay before surgery and Apgar score affecting the amount of bleeding are summarized in Table 4. The overall result indicates that there is no significant difference between the maternal age group, gravidity, the number of previous CS, gestational age at termination of pregnancy, types of CS, length of hospital stay before surgery and Apgarscore. However, the amount of bleeding was found to be significantly more in the patient with intraoperative complication $(\mathrm{P}=0.007)$ and in the patient with the implanted placenta $(\mathrm{P}<0.001)$. Among the 188 included patients, there was no implantation in 120 patients, implantation of $<$ $31.86 \mathrm{~cm}^{2}$ in 17 patients, $\geq 31.86 \mathrm{~cm}^{2}$ in 18 patients and the implantation site were not measurable in 34 patients. The comparison between the implantation and the amount of bleeding is summarized in Table 5. The amount of bleeding was found to be significantly higher in the patients whose implantation site was not measurable (unmeasurable), $(\mathrm{P}<0.001)$ and significantly less amount of bleeding was found in the patient with no placental implantation.

\section{Discussion}

Endometrial damage, poor scar healing at the site of incision, endometrial defects after a CS can lead to villi and the placenta invasion into the muscularis as well as serosalcoat, and probably the bladder and pelvic wall, which is influencing 
Table 4. Predictive factors affecting amount of bleeding.

\begin{tabular}{|c|c|c|c|c|c|}
\hline \multicolumn{2}{|l|}{ Variables } & \multirow{2}{*}{$\begin{array}{c}\text { Cases } \\
121\end{array}$} & \multirow{2}{*}{$\begin{array}{c}\text { Amount of bleeding } \\
900(500,1900)\end{array}$} & \multirow{3}{*}{$\begin{array}{c}\text { Statistical } \\
\text { magnitude } \\
-0.313\end{array}$} & \multirow{3}{*}{$\begin{array}{r}\text { P value } \\
0.754\end{array}$} \\
\hline Maternal Age & $<35$ & & & & \\
\hline (years) & $\geq 35$ & 67 & $900(600,1800)$ & & \\
\hline \multirow[b]{2}{*}{ Gravidity } & $\leq 3$ & 114 & $800(600,1600)$ & \multirow[b]{2}{*}{-1.061} & \multirow[b]{2}{*}{0.298} \\
\hline & $>3$ & 74 & $1050(500,2500)$ & & \\
\hline \multirow{2}{*}{$\begin{array}{l}\text { Number of previous } \\
\text { cesarean section }\end{array}$} & 1 & 163 & $800(500,1850)$ & \multirow{2}{*}{-1.492} & \multirow{2}{*}{0.136} \\
\hline & $\geq 2$ & 25 & $1300(800,1800)$ & & \\
\hline \multirow{2}{*}{$\begin{array}{c}\text { Gestation at } \\
\text { termination } \\
\text { caesarean section } \\
\text { (weeks) }\end{array}$} & $<36$ & 72 & $1000(675,2000)$ & \multirow{2}{*}{-1.668} & \multirow{2}{*}{0.095} \\
\hline & $\geq 36$ & 116 & $800(500,1800)$ & & \\
\hline \multirow{2}{*}{ Types of Surgery } & Elective & 70 & $600(1000,2000)$ & \multirow{2}{*}{-1.259} & \multirow{2}{*}{0.208} \\
\hline & Emergency & 118 & $850(500,1600)$ & & \\
\hline \multirow{2}{*}{$\begin{array}{l}\text { Complication } \\
\text { during surgery }\end{array}$} & yes & 53 & $1100(800,3000)$ & \multirow{2}{*}{-2.701} & \multirow{2}{*}{0.007} \\
\hline & no & 135 & $800(500,1500)$ & & \\
\hline \multirow{2}{*}{$\begin{array}{l}\text { Preoperative stay } \\
\text { (days) }\end{array}$} & $<5$ & 93 & $1000(500,1600)$ & \multirow{2}{*}{-0.572} & \multirow{2}{*}{0.567} \\
\hline & $\geq 5$ & 95 & $850(600,2000)$ & & \\
\hline \multirow{2}{*}{ Apgar score } & $<8$ & 19 & $900(600,1600)$ & \multirow{2}{*}{-0.184} & \multirow{2}{*}{0.854} \\
\hline & $\geq 8$ & 159 & $800(500,1800)$ & & \\
\hline \multirow{2}{*}{$\begin{array}{c}\text { Placental } \\
\text { implantation }\end{array}$} & yes & 69 & $1700(900,3200)$ & \multirow{2}{*}{-6.290} & \multirow{2}{*}{$<0.001$} \\
\hline & no & 119 & $800(500,1150)$ & & \\
\hline
\end{tabular}

Table 5. Comparison between placental implantation and amount of bleeding.

\begin{tabular}{cccc}
\hline & Cases & Amount of bleeding (ml) \\
\hline & No implantation & 119 & $800(400,1150)$ \\
Implantation & $<31.86 \mathrm{~cm}^{2}$ & 17 & $900(650,1500))$ \\
& $\geq 31.86 \mathrm{~cm}^{2}$ & 18 & $1550(1000,3000)$ \\
& Unable measure & 34 & $3000(1000,3200)$ \\
$\chi^{2}$ & & & 46.502 \\
P value & & $<0.001$ \\
\hline
\end{tabular}

factors in the development of placenta previa and placenta accrete [9]. Placenta accrete and intractable post-partum haemorrhage are two important features of PPP [10] [11]. The first-line of treatment comprises of uterine massage, placental removal, uterotonic administration, and uterine balloon tamponade. In failure cases, uterus-sparing measures, such as uterine artery ligation, internal iliac artery ligation, and selective uterine artery embolization are performed, with hysterectomy as a last option. Another conservative surgical approach is compression suture technique, which was found to be efficacious in preventing hys- 
terectomy in $91.7 \%$ of patients [12]. In our hospital, we use a conservative surgical approach: compression suture technique. The other surgical options are technically difficult to perform, needs special skills and included the risk of several serious complications such as vein laceration, ureter injury, and inadvertent ligation of the arterial blood supply to the lower limb.

The main focus of our study was the amount of bleeding and the effectiveness of conservative suture technique in the preservation of fertility with good neonatal outcome in case of PPP. Angstmann et al. stated that the average amount of bleeding during the cesarean section of patients with PPP can be as high as $3000-5000 \mathrm{~mL}$ and the hysterectomy rate has been reported to be very high as $55 \%-75 \%$ [10]. In our study, the average amount of bleeding during the CS was $925 \mathrm{ml}$ and was higher in the elective group $(1000 \mathrm{ml})$ than the emergency group $(850 \mathrm{ml})$. Moreover, depth of placental implantation and area of placental implantation is directly proportional to the amount of bleeding. The amount of bleeding was much higher in unmeasurable cases followed by cases with placental implantation $\geq 31.86 \mathrm{~cm}^{2}$. Furthermore, bleeding was higher in cases with intraoperative complication. PPP is usually associated with adhesion, in our patients, we had 9 cases with extensive adhesion and additionally, adhesiolysis was performed. Ureter stent was placed in 28 patients due to ureteric complication intra-operatively. We had difficulty in placental separation and delivery due to placental implantation. In spite of careful placental separation, 17 patients had a uterine injury during the procedure and uterine repair was done. All of our patients received uterotonic agents, modified $\mathrm{CHO}$ sutures applied in placental bed and additional B-lynch suture was placed in 26 patients. In refractory cases, the last and ultimate treatment of post-partum haemorrhage is a hysterectomy. In our study, hysterectomy was done in 5 patients $(2.6 \%)$ which is very low compared to other studies where the rate is very high. Neonatal outcome was satisfactory with good neonatal weight and proper Apgar score. Neonatal weight was found to be $2803 \pm 635$ grams. Neonatal weight was significantly high in the elective group in comparison with the emergency group and was not affected by suture techniques.

Huang et al. described that temporary ligation of the infrarenal abdominal aorta provides a safe and effective method for controlling intraoperative blood loss during CS in patients with PPP. Furthermore, the technique may deliver an occasion to conserve fertility by circumventing a cesarean hysterectomy [13]. Jun et al. Stated that pre-cesarean prophylactic balloon placement (PBP) in the internal iliac artery was a safe and effective method that could diminish the frequency of both postpartum haemorrhage and hysterectomy among women with PPP [14]. Hysterectomy rate was $5 \%$ in his study which is higher in comparison to our study. Most of the authors mentioned the use of infrarenal abdominal artery balloon occlusion, PBP placement in the internal iliac artery, embolization of the internal iliac or uterine arteries [14] [15] [16]. However, all of these methods have their own drawbacks including sophisticated skilled manpower and 
advanced setup whereas the conservative suture methods are simple, less time consuming, feasible, can be performed with less skilled manpower and is cost effective [17].

There are numerous limitations to this study. Firstly, this was a retrospective study and all the patients demographic, clinical as well as follow up data were based on clinical records. Hence, there were unavoidable biases including selection and information bias in this retrospective study. In conclusion, this study demonstrated that suture technique during the cesarean delivery is a feasible, safe and effective alternative conservative surgical technique for the management of bleeding in case of pernicious placenta Previa. Besides good surgical outcome and the proper neonatal result this technique also reduces the rate of hysterectomy, thus conserving the fertility for subsequent pregnancies.

\section{Acknowledgements}

The authors would like to thank Dr. Shashanki Chatatut (email: shashankichataut23@gmail.com) and Dinesh Koju (email:dineshkoju50@gmail.com) for his valuable opinion on the manuscript. The authors report no conflict of interest.

\section{Conflicts of Interest}

The authors declare no conflicts of interest regarding the publication of this paper.

\section{References}

[1] Betran, A.P., Ye, J., Moller, A.B., Zhang, J., Gulmezoglu, A.M. and Torloni, M.R. (2016) The Increasing Trend in Caesarean Section Rates: Global, Regional and National Estimates: 1990-2014. PloS One, 11, e0148343.

https://doi.org/10.1371/journal.pone.0148343

[2] Gregory, K.D., Jackson, S., Korst, L. and Fridman, M. (2012) Cesarean versus Vaginal Delivery: Whose Risks? Whose Benefits? American Journal of Perinatology, 29, 7-18. https://doi.org/10.1055/s-0031-1285829

[3] Gurol-Urganci, I., Bou-Antoun, S., Lim, C.P., Cromwell, D.A., Mahmood, T.A., Templeton, A. and van der Meulen, J.H. (2013) Impact of Caesarean Section on Subsequent Fertility: A Systematic Review and Meta-Analysis. Human Reproduction, 28, 1943-1952. https://doi.org/10.1093/humrep/det130

[4] Chattopadhyay, S.K., Kharif, H. and Sherbeeni, M.M. (1993) Placenta Praevia and Accreta after Previous Caesarean Section. European Journal of Obstetrics, Gynecology, and Reproductive Biology, 52, 151-156. https://doi.org/10.1016/0028-2243(93)90064-J

[5] Chen, Z., Li, J., Shen, J., Jin, J., Zhang, W. and Zhong, W. (2016) Direct Puncture Embolization of the Internal Iliac Artery during Cesarean Delivery for Pernicious Placenta Previa Coexisting with Placenta Accreta. International Journal of Gynaecology and Obstetrics, 135, 264-267. https://doi.org/10.1016/j.ijgo.2016.05.018

[6] Sivan, E., Spira, M., Achiron, R., Rimon, U., Golan, G., Mazaki-Tovi, S. and Schiff, E. (2010) Prophylactic Pelvic Artery Catheterization and Embolization in Women with Placenta Accreta: Can It Prevent Cesarean Hysterectomy? American Journal of Perinatology, 27, 455-461. https://doi.org/10.1055/s-0030-1247599 
[7] Joshi, V.M., Otiv, S.R., Majumder, R., Nikam, Y.A. and Shrivastava, M. (2007) Internal Iliac Artery Ligation for Arresting Postpartum Haemorrhage. BJOG, 114, 356-361. https://doi.org/10.1111/j.1471-0528.2006.01235.x

[8] Diemert, A., Ortmeyer, G., Hollwitz, B., Lotz, M., Somville, T., Glosemeyer, P., Diehl, W. and Hecher, K. (2012) The Combination of Intrauterine Balloon Tamponade and the B-Lynch Procedure for the Treatment of Severe Postpartum Hemorrhage. American Journal of Obstetrics and Gynecology, 206, 65.e1-65.e4. https://doi.org/10.1016/j.ajog.2011.07.041

[9] Garmi, G. and Salim, R. (2012) Epidemiology, Etiology, Diagnosis, and Management of Placenta Accreta. Obstetrics and Gynecology International, 2012, Article ID: 873929. https://doi.org/10.1155/2012/873929

[10] Angstmann, T., Gard, G., Harrington, T., Ward, E., Thomson, A. and Giles, W. (2010) Surgical Management of Placenta Accreta: A Cohort Series and Suggested Approach. American Journal of Obstetrics and Gynecology, 202, 38.e1-38.e9. https://doi.org/10.1097/01.aoa.0000389612.78757.be

[11] Hull, A.D. and Moore, T.R. (2011) Multiple Repeat Cesareans and the Threat of Placenta Accreta: Incidence, Diagnosis, Management. Clinics in Perinatology, 38, 285-296. https://doi.org/10.1016/j.clp.2011.03.010

[12] Akbayir, O., Corbacioglu Esmer, A., Cilesiz Goksedef, P., Ekiz, A., Akca, A., Guraslan, B. and Akagunduz, G. (2013) Single Square Hemostatic Suture for Postpartum Hemorrhage Secondary to Uterine Atony. Archives of Gynecology and Obstetrics, 287, 25-29. https://doi.org/10.1007/s00404-012-2509-x

[13] Huang, S., Xia, A., Jamail, G., Long, M. and Cheng, C. (2017) Efficacy of Temporary Ligation of Infrarenal Abdominal Aorta during Cesarean Section in Pernicious Placenta Previa. Zhong Nan Da Xue Xue Bao. Yi Xue Ban = Journal of Central South University. Medical Sciences, 42, 313-319.

[14] Dai, M.J., Jin, G.X., Lin, J.H., Zhang, Y., Chen, Y.Y. and Zhang, X.B. (2018) Pre-Cesarean Prophylactic Balloon Placement in the Internal Iliac Artery to Prevent Postpartum Hemorrhage among Women with Pernicious Placenta Previa. International Journal of Gynaecology and Obstetrics, 142, 315-320. https://doi.org/10.1002/ijgo.12559

[15] Li, N., Yang, T., Liu, C. and Qiao, C. (2018) Feasibility of Infrarenal Abdominal Aorta Balloon Occlusion in Pernicious Placenta Previa Coexisting with Placenta Accrete. BioMed Research International, 2018, Article ID: 4596189. https://doi.org/10.1155/2018/4596189

[16] Xu, J.Q. (2015) Effectiveness of Embolization of the Internal Iliac or Uterine Arteries in the Treatment of Massive Obstetrical and Gynecological Hemorrhages. European Review for Medical and Pharmacological Sciences, 19, 372-374.

[17] Zhu, B., Yang, K. and Cai, L. (2017) Discussion on the Timing of Balloon Occlusion of the Abdominal Aorta during a Caesarean Section in Patients with Pernicious Placenta Previa Complicated with Placenta Accreta. BioMed Research International, 2017, Article ID: 8604849. https://doi.org/10.1155/2017/8604849 